\title{
Nerve potentials and afferent conduction velocities in the differential diagnosis of amyotrophy of the hand
}

\author{
ANICA JUŠIĆ AND STANKO MILIĆ \\ From the Department of Neurology, School of Medicine of the University of Zagreb, \\ Zagreb, and City Hospital, Osijek, Yugoslavia
}

SUMMARY Nerve action potentials recorded over the elbow after stimulation of the wrist were studied in patients with hand amyotrophy of different origin. In amyotrophic lateral sclerosis the amplitude of nerve action potentials does not change significantly even with extreme muscle wasting and loss of motor units.

Studies of multisegmental afferent conduction velocities may demonstrate a strictly localized lesion with normal values above the compression.

The site of the lesion is the first question in the differential diagnosis of amyotrophy of the small muscles of the hand. In some of our earlier studies we tried to answer it with measurements of motor conduction velocities in four nerve segments: below-elbow to wrist, above-elbow to below-elbow, axilla to above-elbow, and supraclavicular fossa-axilla (Jušić, 1966). Gilliatt and Sears (1958) used sensory nerve action potentials for the same purpose in patients suffering from diffuse or localized nerve lesions. The analysis of so-called 'mixed' nerve potentials seemed also to be of value in differential diagnosis.

\section{METHODS}

The studies were done on median and ulnar nerve in 15 patients suffering from amyotrophic lateral sclerosis with extreme involvement of the small muscles of the hand and on 15 patients with the same illness but with a lesser degree of hand amyotrophy. Sixteen patients with hand amyotrophy of other origin (eight, polyneuropathy; three, ulnar groove syndrome; three, carpal tunnel syndrome; one lower brachial plexus syndrome; and one antebrachial tumour) were also analysed.

The nerves were stimulated at the wrist with an electronic stimulator (Multistim, DISA) using uninsulated bipolar needle electrodes and nerve potentials were recorded over the elbow with the same kind of needles. The placement was checked by stimulating at the wrist or over the elbow and recording with concentric needle electrodes from the $\mathrm{m}$. opponens pollicis or $\mathrm{m}$. abductor digiti minimi. The position of the stimulating electrode was changed along the nerve until the threshold for evoked muscle response was below $3 \mathrm{~V}$. The nerve action potential was usually recorded just above the elbow through the needles previously used for stimulation. The stimulating strengths were three to four times stimulus threshold, the pulses rectangular, $0.2 \mathrm{msec}$ in duration. The evoked potentials were directly displayed on the screen of a Tektronix 565 oscilloscope without superposition of responses.

\section{RESULTS}

AMYOTROPHIC LATERAL SCLEROSIS The patients of this group were all younger than 50 years of age. The illness was rather rapidly progressing. More or less symmetrical involvement of the small muscles of the hands was the outstanding feature. The patients were divided in two groups; group 1 with a high degree of atrophy, single motor unit innervation pattern on electromyography and small direct muscle response in the muscle belonging to the nerve stimulated. Group 2 differed from the previous one in the lesser degree of atrophy and intermediate innervation pattern on the oscilloscope screen.

The range of sizes of nerve potentials in both groups and in controls is shown in the Table.

The results can be summarized as follows: in group 1, with a high degree of muscle involve- 
TABLE

ment, the range of nerve potentials amplitudes was the same as in the healthy controls; in group 2 the mean amplitude was slightly greater than in the normal subjects. No statistically significant difference between the three groups was found.

In Fig. 1 the amplitude of the direct muscle response in (a) and (b) is extremely reduced (150 $\mu \mathrm{V})$ corresponding to the 'single unit' innervation pattern seen at maximal voluntary effort. The nerve action potential above the elbow, evoked with the electrodes in the same position
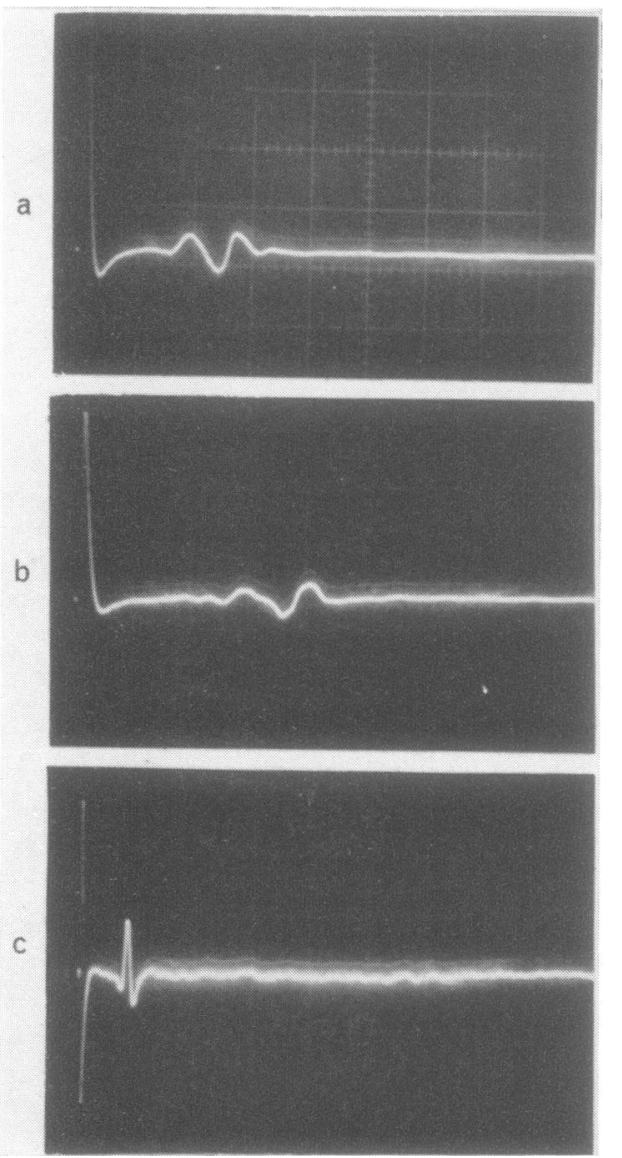

FIG. 1 Amyotrophic lateral sclerosis, group 1. (a) and (b): M. opponens pollicis. Tracings $0 \cdot 20 \mathrm{mV}$ /division, 5 msec/division. Muscle response evoked from wrist (a), over the elbow (b). (c): $N$. medianus. $0.02 \mathrm{mVI}$ division, 5 msec/division. Nerve potential recorded over the elbow, with stimulation at the wrist.

\section{RANGE OF AMPLITUDE OF NERVE ACTION POTENTIALS}

\begin{tabular}{|c|c|c|c|}
\hline $\begin{array}{l}\text { Amplitude of } \\
\text { response }(\mu V)\end{array}$ & $\underset{\text { (no.) }}{A L S \text { Group } 1}$ & $\underset{\text { (no.) }}{A L S \text { Group } 2}$ & $\begin{array}{c}\text { Controls } \\
\text { (no.) }\end{array}$ \\
\hline$<10$ & 0 & 0 & 0 \\
\hline $10-19$ & 5 & 5 & 10 \\
\hline $20-29$ & 5 & 2 & 17 \\
\hline $30-39$ & 3 & 1 & 6 \\
\hline $40-49$ & 1 & 1 & 7 \\
\hline $50-59$ & 1 & 6 & 3 \\
\hline \multirow[t]{3}{*}{$>60$} & 0 & 0 & 0 \\
\hline & $\begin{array}{r}\bar{x}_{1}=24 \cdot 4 \\
S d=11 \cdot 1 \\
S \bar{x}_{1}=2 \cdot 9\end{array}$ & $\begin{aligned} \overline{\mathrm{x}}_{2} & =32.7 \\
\mathrm{Sd}_{2} & =16.8 \\
\mathrm{~S} \tilde{\mathrm{x}}_{2} & =4.3\end{aligned}$ & $\begin{aligned} \overline{\mathrm{x}}_{3} & =26 \cdot 1 \\
\mathrm{Sd}_{3} & =9 \cdot 5 \\
\mathrm{~S} \overline{\mathrm{x}}_{3} & =1 \cdot 5\end{aligned}$ \\
\hline & \multicolumn{2}{|c|}{$\begin{array}{c}t_{1}, 3-1.91 \\
\mathbf{P}>0.05\end{array}$} & .45 \\
\hline
\end{tabular}

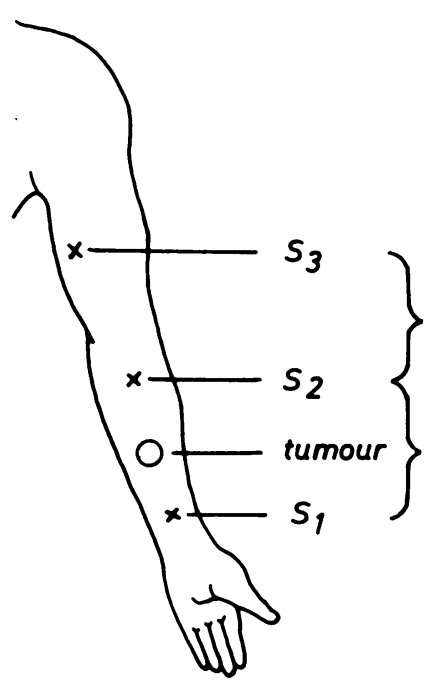

FIG. 2a. Diagram of case with a forearm tumour.

as for the evoked muscle responses, was $30 \mu \mathrm{V}$ in amplitude and of normal shape and duration.

POLYNEUROPATHY In eight cases with clinical signs and symptoms of mixed polyneuropathy the nerve potentials could not be elicited even in the lesions of lesser degree.

LOCALIZED COMPRESSION SYNDROME No nerve action potential could be recorded in the case of hand amyotrophy with low blood pressure and low oscillometric amplitude at the involved site. 
The motor conduction velocities measured in four parts of the ulnar nerve were: $10.5 \mathrm{~m} / \mathrm{sec}$ in the supraclavicular fossa to axilla segment, 30.0 $\mathrm{m} / \mathrm{sec}$ in axilla to above-elbow segment, 44.8 $\mathrm{m} / \mathrm{sec}$ and $43.9 \mathrm{~m} / \mathrm{sec}$ in two next ones. The duration of evoked (M) potentials were (from proximal to distal): $40 \mathrm{msec}, 40 \mathrm{msec}, 25 \mathrm{msec}$, $15 \mathrm{msec}$, and $15 \mathrm{msec}$.

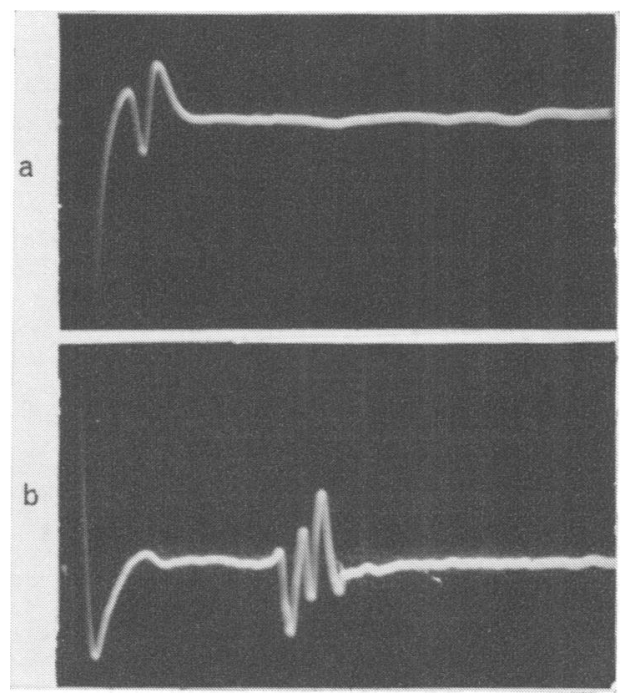

FIG. 2b. Bisegmental analysis of afferent conduction velocities in a case with a forearm tumour. $N$. medianus. $0.02 \mathrm{mV} /$ div. (a) nerve action potential. $S_{2}-S_{3}$, 2 msec/div. (b) nerve action potential. $S_{1}-S_{2}$, $5 \mathrm{msec} / \mathrm{div}$.

In three cases of ulnar groove syndrome, no nerve action potentials could be recorded with stimulation at the wrist and recording above the elbow. The motor conduction velocities in a representative case were: axilla to above-elbow segment $72 \mathrm{~m} / \mathrm{sec}$; above-elbow to below-elbow segment $22 \mathrm{~m} / \mathrm{sec}$; and $24 \mathrm{~m} / \mathrm{sec}$ in the belowelbow to wrist segment. The duration of the evoked (M) potentials were 18 and $12 \mathrm{msec}$ if elicited distal to the site of the lesion and 32 msec if elicited above the lesion.

In three cases of carpal tunnel syndrome stimulation of the wrist resulted in nerve action potentials above the elbow, of normal amplitude. In all of them there was no sensory potential elicitable at the wrist.

In a case with slight thenar atrophy and with a small tumour in the forearm the afferent conduction velocity was measured in two segments (Fig. 2b) of the median nerve. In the tumour region it was as low as $5 \mathrm{~m} / \mathrm{sec}$. The nerve action potential recorded in $\mathrm{S}_{2}$ was of normal amplitude $(43 \mu \mathrm{V})$ but of long duration $(6 \mathrm{msec})$. In the next segment over the elbow with the stimulation point at $S_{2}$ and derivation at $S_{3}$ the conduction velocity was within the normal range $(69.5$ $\mathrm{m} / \mathrm{sec}$ ), with nerve action potential of normal amplitude and duration. The values of motor conduction velocity were as follows: $45 \cdot 1 \mathrm{~m} / \mathrm{sec}$ for the $S_{1}-S_{2}$ segment, and $65.3 \mathrm{~m} / \mathrm{sec}$ for the $\mathrm{S}_{2}-\mathrm{S}_{3}$ segment.

\section{DISCUSSION}

Identification of sensory nerve action potentials of median and ulnar nerve after electrical stimulation in patients with amyotrophic lateral sclerosis (Fincham and Van Allen, 1964) and in syringomyelia (Fincham and Cape, 1968) pointed to the usefulness of these studies in differentiating intraspinal lesions from peripheral neuropathy. These action potentials were consistently found in the presence of severe muscular wasting of amyotrophic lateral sclerosis, which supports the clinical finding of normal sensory function in this disease. The same results were obtained by Ertekin (1967). The sensory conduction velocities between fingers and wrist and between wrist, elbow, and axilla were normal. The amplitude, shape, and duration of the sensory action potentials were also normal. The velocity of 'mixed' median nerve action potentials between wrist, elbow, and axilla was of the same order as the velocity of the sensory fibres and slightly higher than in motor fibres.

The diagnostic value of these mixed nerve potentials was the point of interest in our studies on motor neurone disease. Muscle atrophy was severe and loss of motor units was extreme. The amplitude of nerve action potentials was the same as in the normal controls. By the technique of Dawson and Scott (1949) the median or ulnar nerve at the level of the wrist was stimulated electrically and the action potential of the affer- 
ent volley recorded over the nerve trunk at a higher level in the arm. The afferent volley contained in their opinion, both sensory impulses and antidromic impulses in motor fibres and gave rise to diphasic or triphasic action potentials. To eliminate the contribution of motor fibres, Dawson (1956) modified his original technique and stimulated the digital nerves. The sensory potentials recorded were similar in form to the mixed nerve action potentials but, being derived from digital nerves, they were considerably smaller in amplitude.

Our group 1 with extreme hand amyotrophy provided a model of a kind of elimination of motor fibres. Despite the huge loss of motor units the amplitude of the nerve action potentials did not change significantly. This requires explanation if the amplitude is dependent on the number of fibres excited. With motor fibres almost entirely lost, the amplitude of action potentials remains within the normal range.

The nerve action potential is formed from the summed potential of a large number of nerve fibres and its appearance depends upon the passage of a synchronous volley under the recording electrodes. Slowing of nerve conduction has the effect of scattering the time of arrival of different impulses at the recording electrodes and thus of reducing the peak amplitude of the compound action potential. The amplitude of nerve action potential in our case with a tumour of the forearm has remained within the normal range.
The duration and shape were abnormal. The point of interest was that the extreme slowing of $z_{\mathbb{D}}$ afferent nerve conduction remained strictly localized, the observation made in multisegmen- of tal motor conduction studies (Jušić, 1966). The values of motor conduction velocities in that 0 case were $7 \mathrm{~m} / \mathrm{sec}$ in the elbow segment. The proximal value was $55 \mathrm{~m} / \mathrm{sec}$, and distal $54 \mathrm{~m} / \mathrm{s}$.

The evoking of nerve potentials may be of interest in the differential diagnosis of the carpal $\vec{\Rightarrow}$ tunnel syndrome. With the sensory nerve action potential and sensory nerve conduction to the wrist impaired or lost, the nerve action potential over the elbow can be within the normal range. Localized demyelination, as in the tumour case, could be the explanation for the phenomenon.

\section{REFERENCES}

Dawson, G. D., and Scott, J. W. (1949). The recording of nerve action potentials through skin in man. Journal of Neurology, Neurosurgery, and Psychiatry, 12, 259-267.

Ertekin, C. (1967). Sensory and motor conduction in motor neurone disease. Acta Neurologica Scandinavica, 43, 499- के 512.

Fincham, R. W., and Cape, C. A. (1968). Sensory nerve coô.

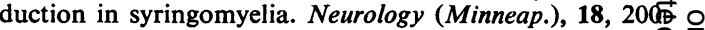
201.

Fincham, R. W., and Van Allen, M. W. (1964). Sensory nerie conduction in amyotrophic lateral sclerosis. Neurolog (Minneap.), 14, 31-33.

Gilliatt, R. W., and Sears, T. A. (1958). Sensory nerve actio potentials in patients with peripheral nerve lesions. Journ of Neurology, Neurosurgery, and Psychiatry, 21, 109-118.

Jušić, A. (1966). Stimulaciona elektromiografija u dijagnoş tici visine neuralne lezije na ruci. Neuropsihijatrija (Zagreb), 14 67-75. 